\title{
Low expression of BEX1 predicts poor prognosis in patients with esophageal squamous cell cancer
}

\author{
HAI-TAO GENG ${ }^{1,2^{*}}$, ZHI-WEN CHENG ${ }^{1,2^{*}}$, RUI-JUAN CAO ${ }^{3 *}$, ZHEN-BO WANG $^{2}$, SHAO-ZHI XING ${ }^{2}$, \\ CHEN GUO $^{2}$, FENG WANG ${ }^{2}$, CHANG-MIN LIU $^{2}$, SHAO-SHUI CHEN ${ }^{2}$ and YU-FENG CHENG ${ }^{1}$ \\ ${ }^{1}$ Department of Radiation Oncology, Qilu Hospital of Shandong University, Jinan, Shandong 250012; \\ Departments of ${ }^{2}$ Oncology and ${ }^{3}$ Otorhinolaryngology-Head and Neck Surgery, \\ Binzhou Medical University Hospital, Binzhou, Shandong 256603, P.R. China
}

Received March 30, 2018; Accepted August 9, 2018

DOI: $10.3892 /$ or.2018.6647

\begin{abstract}
The brain expressed x-linked gene 1 (BEX1) is a member of the BEX family and is aberrantly expressed in many cancers. However, the clinical significance of BEX1 expression level and its role in the pathology of esophageal squamous cell cancer (ESCC) remain unknown. In the present study, we determined BEX1 expression in the tumor and adjacent normal tissues from 118 ESCC patients by immunohistochemistry and determined the proliferation and growth of ESCC cells following ectopic overexpression of BEX1 in cultured cells and in mouse-ESCC xenografts. We observed that BEX1 was downregulated in ESCC tissues compared to adjacent normal tissues, and low BEX1 expression was significantly associated with larger ESCC tumor volume $(\mathrm{P}<0.001)$, advanced $\mathrm{T}$ stage $(\mathrm{P}=0.011)$ and advanced clinical stage $(\mathrm{P}=0.039)$. Additionally, survival analysis revealed that low expression of BEX1 significantly predicted poor prognosis in patients with ESCC $(\mathrm{P}<0.001)$. Multivariate analysis revealed that low $\mathrm{BEX} 1$ expression was an independent prognostic factor of poor survival $(\mathrm{P}=0.039)$. In vitro analysis revealed that overexpression of BEX1 inhibited ESCC cell proliferation and colony formation. Furthermore, in vivo tumorigenesis assays revealed that ectopic overexpression of BEX1 suppressed ESCC tumor growth in mice. Further immunoblotting analysis demonstrated that BEX1 upregulation led to reduced expression and phosphorylation of $N F-\kappa B$
\end{abstract}

Correspondence to: Dr Yu-Feng Cheng, Department of Radiation Oncology, Qilu Hospital of Shandong University, 107 Wenhua Road West, Jinan, Shandong 250012, P.R. China

E-mail: qiluchengyf@163.com

*Contributed equally

Key words: BEX1, esophageal squamous cell cancer, prognosis, proliferation, $\mathrm{NF}-\mathrm{\kappa B}$ p65, indicating inhibition of the NF- $\kappa \mathrm{B}$ signaling pathway by BEX1. Our findings indicated that low BEX1 expression may be an independent prognostic marker for poor survival and may serve as a potential target for ESCC therapy.

\section{Introduction}

Esophageal cancer is the eighth most common malignancy in the world and the fifth most commonly diagnosed cancer in China $(1,2)$. Esophageal squamous cell cancer (ESCC) is the main histological subtype of esophageal cancer in China. Spicy food consumption, alcohol drinking and smoking increase the risk of esophageal cancer (3). Due to insidious early symptoms, ESCC is often diagnosed at advanced stages. Despite advances in multimodal therapy, the 5 year survival rate of ESCC patients remains at $\sim 10-15 \%$ (4). Therefore, it is urgent to better understand the molecular mechanisms and identify biomarkers for the diagnosis, prognosis and treatment of ESCC.

The human brain expressed X-linked gene family consists of BEX1, BEX2, BEX3, BEX4 and BEX5, which are highly conserved in phylogeny $(5,6)$. The human BEX family proteins were first identified in the central nervous system and play an important role in neuronal differentiation and regeneration. Further studies have revealed that BEX family members are involved in the regulation of the cell cycle and apoptosis as well as muscle differentiation. Emerging evidence has demonstrated that BEX family proteins are distinctly expressed among different types of cancers, but their roles in tumorigenesis are currently controversial. BEX1 is overexpressed in acute myeloid leukemia (AML) with mixed lineage leukemia (MLL) mutation, indicating that BEX1 plays a role in leukemogenesis (7). However, BEX1 expression was observed to be downregulated in a group of FMS-like tyrosine kinase-3 (FLT3-ITD) driven AML patients (8). Ding et al reported that BEX1 was downregulated in imatinib-resistant chronic myeloid leukemia K562 cell line and overexpression of BEX1 re-sensitized the cells to imatinib-induced apoptosis (9). Gene expression analyses have revealed that BEX1 promoter is hypermethylated in intracranial ependymoma, malignant glioma and oral squamous cell carcinoma (OSCC) (10-12). 
The differential expression and promoter hypermethylation indicated that BEX1 may be a potential tumor suppressor. However, the expression status and clinical significance of $\mathrm{BEX} 1$ expression as well as its role in ESCC remains to be determined.

In the present study, we determined BEX1 protein expression in the tumor and adjacent normal tissues from 118 ESCC patients and evaluated its relationship with clinicopathological parameters and prognosis. We observed that BEX1 was downregulated in late tumor stage ESCC tissues and low expression of BEX1 predicted poor prognosis of patients with ESCC. Furthermore, we assessed BEX1 biological functions in ESCC by in vitro and in vivo assays. We revealed that overexpression of BEX1 inhibited ESCC cell proliferation in vitro and tumor growth in mouse xenografts. In addition, we observed that BEX1 overexpression inhibited $N F-\kappa B$ activation. Our results indicated that BEX1 may function as a tumor suppressor in ESCC and may serve as a potential target for therapies of ESCC.

\section{Materials and methods}

Patients and tissue samples. Tumor tissues and adjacent normal tissues from 118 ESCC patients were collected from Binzhou Medical University Hospital from January 1, 2009 to December 31, 2010. None of the patients had received neoadjuvant therapies prior to surgery. Clinical data including sex, age, smoking history, drinking history, tumor location, tumor size, tumor differentiation, $\mathrm{T}$ stage, lymph node status and clinical stage, were obtained from medical records. The pathological clinical stages of esophageal cancer were classified according to the 7th edition of the UICC/AJCC TNM system. Survival time was determined from the date of surgery to the date of death. Patient follow-ups were conducted every 3-5 months until December 2016 for all patients. This study was approved by the Ethics Committee of Binzhou Medical University Hospital and informed written consent was obtained from every patient.

Immunohistochemistry. All specimens were embedded in paraffin and sectioned at a thickness of $4 \mu \mathrm{m}$. Tissue sections were deparaffinized in a series of alcohols and heated in citrate buffer $(\mathrm{pH}$ 6.0) for antigen retrieval in a microwave oven. Following blocking of nonspecific binding sites with normal goat blood serum, the sections were incubated with BEX1 antibody (dilution 1:50; cat. no. AP10669c; Abgent Biotech Co., Ltd., Suzhou, China) at $4^{\circ} \mathrm{C}$ overnight. The sections were washed with phosphate-buffered saline (PBS) and incubated with horseradish peroxidase (HRP) conjugated secondary antibody (cat. no. PV-6000; OriGene Technologies, Inc., Beijing, China) for $30 \mathrm{~min}$ at room temperature followed by 3 washes with PBS. The sections were then subjected to 3,3'-diaminobenzidine (DAB; ZSGB-Bio, Beijing, China) staining. The sections were counterstained with hematoxylin (ZSGB-Bio) and placed on coverslips with neutrogum nutral balsam (Sinopharm Chemical Reagent Co., Ltd., Shanghai, China). Stained specimens were evaluated by two independent pathologists. For scoring, five fields were randomly selected from each tissue section and at least 100 cells were counted. BEX1 immuno-intensity was classified into three categories:
0 , no staining or weak; 1 , moderate; 2 , strong. The percentage of stained cells was scored as follows: 1, 0-25\%; 2, 26-50\%; $3,51-75 \% ; 4,76-100 \%$. The final score was calculated by multiplying the staining intensity and the percentage of staining cells. The expression level of BEX1 was graded as low (scores, 1-4) or high (scores, 5-8).

Cell lines and cell culture. Human ESCC cell lines (Eca-109 and TE-1) were obtained from the Chinese Academy of Medical Sciences (Shanghai, China). Human EC9706 cells were purchased from Fenghuibio (Changsha, China). Cell lines were cultured in RPMI-1640 medium (Gibco; Thermo Fisher Scientific, Inc., Waltham, MA, USA) containing 10\% fetal bovine serum (FBS; Tianhang Biotechnology Co., Ltd., Huzhou, China). A normal human esophageal epithelial cell line (SHEE) was purchased from Fenghuibio (Changsha, China) and cultured in Dulbecco's modified Eagle's medium (DMEM; Gibco; Thermo Fisher Scientific, Inc.) with $10 \%$ FBS. All cells were incubated in $5 \% \mathrm{CO}_{2}$ atmosphere at $37^{\circ} \mathrm{C}$ and were routinely passaged every 2 or 3 days.

RNA isolation, reverse transcription and real-time PCR analysis (RT-PCR). Total RNA was isolated from tissues or cells using an RNeasy Mini kit (Qiagen GmbH, Hilden, Germany). cDNA was synthesized using the PrimeScript RT reagent kit (Takara Bio, Inc., Otsu, Japan). BEX1 mRNA expression was quantified using SYBR Premix Ex Taq II (Takara Bio, Inc.) and performed with an ABI 7500 System. The primers were as follows: BEX1 forward, 5'-CCTCCCTTTGGATGCTGGTGAAT-3' and reverse, 5'-CTCATCCTTGCCTGTGGTTCTCC-3'; GAPDH forward, 5'-TGACTTCAACAGCGACACCCA-3' and reverse, 5'-CACCCTGTTGCTGTAGCCAAA-3'. GAPDH was used as an internal control. RT-PCR reactions were performed at $95^{\circ} \mathrm{C}$ for $4 \mathrm{~min}$ followed by 40 cycles of $95^{\circ} \mathrm{C}$ for $30 \mathrm{sec}, 58^{\circ} \mathrm{C}$ for $25 \mathrm{sec}$ and $72^{\circ} \mathrm{C}$ for $30 \mathrm{sec}$.

Western blot analysis. Following washing twice with cold PBS, the cells were lysed on ice in RIPA lysis buffer for $30 \mathrm{~min}$ followed by centrifugation with $12,000 \mathrm{x} \mathrm{g}$ at $4^{\circ} \mathrm{C}$ for $15 \mathrm{~min}$. The supernatant total protein was quantified by BCA Protein Assay reagent (Pierce; Thermo Fisher Scientific, Inc.). An equal amount of total protein $(30-50 \mu \mathrm{g})$ was separated on 8-15\% SDS-polyacrylamide gel electrophoresis and then transferred to $0.22-\mu \mathrm{m}$ polyvinylidene fluoride membranes (PVDF) (EMD Millipore, Billerica, MA, USA), which were then blocked with blocking buffer (5\% skim milk in Tris-buffered saline with $0.5 \%$ Tween-20, TBST) at room temperature for $1 \mathrm{~h}$. Following blocking, the membranes were incubated overnight with primary anti-BEX1 antibody (1:300; cat. no. AP10669c), anti-AKT antibody (1:500; cat. no. AP7028B), anti-phosphorylated AKT antibody (1:500; cat. no. AP3434a; Abgent Biotech Co.), anti-p65 antibody (1:100; cat. no. sc-72675; Santa Cruz Biotechnology, Inc., Dallas, TX, USA), anti-phosphorylated p65 (p-p65) (1:100; cat. no. sc-136548; Santa Cruz Biotechnology, Inc.), or anti-GAPDH antibody (1:10,000; cat. no. KC-5G4; KangChen Bio-tech, Shanghai, China) at $4^{\circ} \mathrm{C}$. The HRP-conjugated secondary antibodies $(1: 10,000$; cat. nos. KC-MM-035 and KC-RB-035; KangChen Bio-tech) were diluted at 1:5,000 and incubated with membranes at room 
temperature for $1 \mathrm{~h}$. The bands were visualized using EZ-ECL kit (Biological Industries, Kibbutz Beit Haemek, Israel). GAPDH was used as the loading control. The densitometry of Western blotting band were analyzed by ImageJ software 1.8.0 (National Institutes of Health, Bethesda, MD, USA).

Cell transfection and generation of stable cells. BEX1 expression vector and lentivirus expressing BEX1 were purchased from Vigene Biosciences (Jinan, China). Eca-109 and TE-1 cells were transfected with BEX1 expression construct or an empty vector control via Lipofectamine 2000 (Invitrogen; Thermo Fisher Scientific, Inc.) according to the manufacturer's instructions. Eca-109 and TE-1 cells were transduced with medium containing lentivirus. Stable cells were established by puromycin selection and BEX1 expression was confirmed via RT-PCR and western blotting.

Cell proliferation assay. The role of BEX1 on cell proliferation was evaluated by MTT assay. Briefly, cells were seeded in 96-well plates at a density of $5 \times 10^{3}$ cells/well and cultured for $24 \mathrm{~h}$ in a $5 \% \mathrm{CO}_{2}$ atmosphere at $37^{\circ} \mathrm{C}$. Then, MTT solution was added to each well at a concentration of $5 \mathrm{mg} / \mathrm{ml}$ and incubated at $37^{\circ} \mathrm{C}$ for $4 \mathrm{~h}$. Subsequently, the culture solution was removed and DMSO was added. The absorbance was determined at $490 \mathrm{~nm}$ with a spectrophotometer.

Colony formation assay. A colony formation assay was performed in a 6-well plate. Up to 500 cells were plated in one well and cultured in $4 \mathrm{ml}$ of RPMI-1640 medium (with 10\% FBS) for two weeks. Then, the colonies were fixed and stained with $0.5 \%$ crystal violet for $20 \mathrm{~min}$. Cell clusters consisting of $>50$ cells were defined as a colony and all the colonies were counted under a light microscope.

Cell cycle and apoptosis analysis. Cells were harvested and fixed in $70 \%$ ethanol at $4^{\circ} \mathrm{C}$ for $24 \mathrm{~h}$. Following washing with cold PBS, the cells were incubated with RNase at $37^{\circ} \mathrm{C}$ for $30 \mathrm{~min}$, stained with propidium iodide (PI) for $30 \mathrm{~min}$, and subjected to cell cycle distribution analysis using a flow cytometer (Beckman Coulter, Brea, CA, USA). For apoptosis analysis, the cells were stained with both FITC-Annexin V and PI (BioLegend, Inc., San Diego, CA, USA) and subjected to flow cytometric analysis.

Xenograft tumor assay. Five-week-old, female nude mice were obtained from the Shanghai Laboratory Animal Center (Shanghai, China) and used to establish xenograft models. In brief, $1 \times 10^{6}$ Eca-109 cells stably expressing BEX1 or empty vector were suspended in $150 \mu \mathrm{l}$ of PBS and subcutaneously injected into the flank of nude mice. The length (L) and width (W) of the tumor were measured every 4 days and the tumor volume was calculated as follows: $\mathrm{L} \times \mathrm{W} \times \mathrm{W} / 2$. The tumor weight was determined after the mice were sacrificed by cervical dislocation. The Animal Committee of Binzhou Medical University approved all the experimental protocols and animal handling procedures. All experimental procedures and postoperative animal care were conducted in accordance with the guidelines for the Care and Use of Laboratory Animals from the National Institutes of Health (Bethesda, MD, USA).
$N F-\kappa B$-luciferase reporter assay. ESCC cells stably expressing BEX1 were transfected with an NF- $\kappa \mathrm{B}$-luciferase expression vector (Genomeditech, Shanghai, China). At $24 \mathrm{~h}$ post-transfection, the cells were stimulated with or without 15 ng/ml TNFa (Sangon Biotech Co., Ltd., Shanghai, China) for $24 \mathrm{~h}$. The cells were collected and analyzed for luciferase activities using the Dual-Luciferase Reporter assay system (Promega Corp., Madison, WI, USA). Luciferase activity values were normalized to the expression level of the control vector.

Statistical analysis. All data were statistically analyzed by SPSS software 16.0 (SPSS, Inc., Chicago, IL, USA). A Chi-square test was used to assess the relationship between the expression of BEX1 protein and the clinicopathological characteristics. The Kaplan-Meier method was used to draw the survival curve and the log-rank test was performed to analyze the survival data. Cox's proportional hazards model was performed to analyze variables associated with survival. All data were represented as the mean \pm standard deviation (SD). Student's t-tests were used to compare the data between the two groups. $\mathrm{P}<0.05$ was considered to indicate a statistically significant difference.

\section{Results}

The expression of BEX1 in ESCC tumor tissues and cell lines. The protein expression of BEX1 was determined in 118 pairs of ESCC tumor and adjacent normal tissues via immunohistochemical analysis. As displayed in Fig. 1A, the immunoreactivity of BEX1 was observed in the nucleus and the cytoplasm. Low BEX1 expression was observed in 72 cases of tumor tissues $(61.02 \%)$ and 9 cases of normal tissues (7.63\%, Fig. 1B). We further assessed the expression of BEX1 in normal human esophageal epithelial cells (SHEE) and three ESCC cell lines (TE-1, Eca-109 and EC9706). RT-PCR analysis revealed that BEX1 mRNA expression in ESCC cell lines was significantly lower than that of SHEE cells (Fig. 1C). Consistently, western blot analysis revealed that BEX1 protein levels in ESCC cell lines were significantly lower than that of SHEE cells (Fig. 1D). These results revealed BEX1 to be downregulated in ESCC.

Association of BEX1 expression with clinicopathological characteristics of ESCC. Subsequently, we classified the 118 ESCC patients into the BEX1 low-expression group $(n=72)$ and high-expression group $(n=46)$, and systematically analyzed the association of BEX1 expression with clinicopathological characteristics via chi-square test. The clinicopathological variables and BEX1 expression are listed in Table I. There was a statistically significant negative association between the expression level of BEX1 and tumor length $(\mathrm{P}<0.001)$, T stage $(\mathrm{P}=0.011)$ and pTNM stage $(\mathrm{P}=0.039)$ (Table $\mathrm{I})$. However, there was no significant association of BEX1 expression with sex $(\mathrm{P}=0.688)$, age $(\mathrm{P}=0.312)$, smoking history $(\mathrm{P}=0.266)$, alcohol drinking history $(\mathrm{P}=0.099)$, tumor location $(\mathrm{P}=0.604)$, differentiation $(\mathrm{P}=0.077)$ and $\mathrm{N}$ stage $(\mathrm{P}=0.178)$. These data indicated that low expression of BEX1 predicted poor prognosis of ESCC patients and that BEX1 may be an independent negative prognostic factor for overall survival rates. 
Table I. Relationship between the number of cases with BEX1 expression and the clinicopathological variables of ESCC patients.

\begin{tabular}{|c|c|c|c|c|}
\hline \multirow[b]{2}{*}{ Variables } & \multirow[b]{2}{*}{ Case number $(\mathrm{n}=118)$} & \multicolumn{3}{|c|}{ BEX1 expression (\%) } \\
\hline & & Low $(n=72)$ & High $(n=46)$ & P-value \\
\hline Sex & & & & 0.688 \\
\hline Male & 97 & $60(61.9)$ & $37(38.1)$ & \\
\hline Female & 21 & $12(57.1)$ & $9(42.9)$ & \\
\hline Age (years) & & & & 0.312 \\
\hline$<60$ & 60 & $39(65.0)$ & $21(35.0)$ & \\
\hline$\geq 60$ & 58 & $33(56.9)$ & $25(43.1)$ & \\
\hline Smoking history & & & & 0.266 \\
\hline Never or light & 44 & $24(54.5)$ & $20(45.5)$ & \\
\hline Heavy & 74 & $48(64.9)$ & $26(35.1)$ & \\
\hline Alcohol drinking history & & & & 0.099 \\
\hline Never or light & 48 & $25(52.1)$ & $23(47.9)$ & \\
\hline Heavy & 70 & $47(67.1)$ & $23(32.9)$ & \\
\hline Tumor location & & & & 0.604 \\
\hline Cervical & 1 & $1(100.0)$ & $0(0.0)$ & \\
\hline Upper thoracic & 12 & $6(50.0)$ & $6(50.0)$ & \\
\hline Middle thoracic & 60 & $39(65.0)$ & $21(35.0)$ & \\
\hline Lower thoracic & 45 & $26(57.8)$ & $19(42.2)$ & \\
\hline Tumor length $(\mathrm{cm})$ & & & & $<0.001$ \\
\hline$<4$ & 57 & $22(38.6)$ & $35(61.4)$ & \\
\hline$\geq 4$ & 61 & $50(82.0)$ & $11(18.0)$ & \\
\hline Differentiation & & & & 0.077 \\
\hline Poor & 19 & $15(78.9)$ & $4(21.1)$ & \\
\hline Moderate & 53 & $34(64.2)$ & $19(35.8)$ & \\
\hline Well & 46 & $23(50.0)$ & $23(50.0)$ & \\
\hline T stage & & & & 0.011 \\
\hline $\mathrm{T} 1$ & 10 & $3(30.0)$ & $7(70.0)$ & \\
\hline $\mathrm{T} 2$ & 17 & $7(41.2)$ & $10(58.8)$ & \\
\hline T3 & 69 & $44(63.8)$ & $25(36.2)$ & \\
\hline $\mathrm{T} 4$ & 22 & $18(81.8)$ & $4(18.2)$ & \\
\hline N stage & & & & 0.178 \\
\hline No & 58 & $32(55.2)$ & $26(44.8)$ & \\
\hline $\mathrm{N} 1$ & 26 & $15(57.7)$ & $11(42.3)$ & \\
\hline $\mathrm{N} 2$ & 29 & $20(69.0)$ & $9(31.0)$ & \\
\hline N3 & 5 & $5(100.0)$ & $0(0.0)$ & \\
\hline pTNM stage & & & & 0.039 \\
\hline I & 16 & $5(31.2)$ & $11(68.8)$ & \\
\hline II & 45 & $27(60.0)$ & $18(40.0)$ & \\
\hline III & 57 & $40(70.2)$ & $17(29.8)$ & \\
\hline
\end{tabular}

Low expression of BEX1 is associated with poor clinical outcome of ESCC patients. We further performed Kaplan-Meier analysis to determine BEX1 expression level in association to patient survival time. The 5-year survival rate of ESCC patients with high BEX1 expression was $63.04 \%$ (29/46), while that of patients with low BEX1 expression was $29.17 \%(21 / 72)$. The difference was statistically significant $(\mathrm{P}<0.001$; Fig. 2$)$. Univariate $\mathrm{COX}$ regression analysis demonstrated that
BEX1 $(\mathrm{P}<0.001)$, tumor length $(\mathrm{P}=0.002)$, $\mathrm{T}$ stage $(\mathrm{P}<0.001)$, $\mathrm{N}$ stage $(\mathrm{P}<0.001)$ and pTNM stage $(\mathrm{P}<0.001)$ were statistically associated with overall survival (Table II). Multivariate COX regression analysis revealed that the expression level of BEX1 $(\mathrm{P}=0.039)$ as well as $\mathrm{T}$ stage $(\mathrm{P}=0.034)$, $\mathrm{N}$ stage $(\mathrm{P}=0.007)$ and pTNM stage $(\mathrm{P}=0.025)$, were independent prognostic factors for overall survival of ESCC patients (Table II). 
A

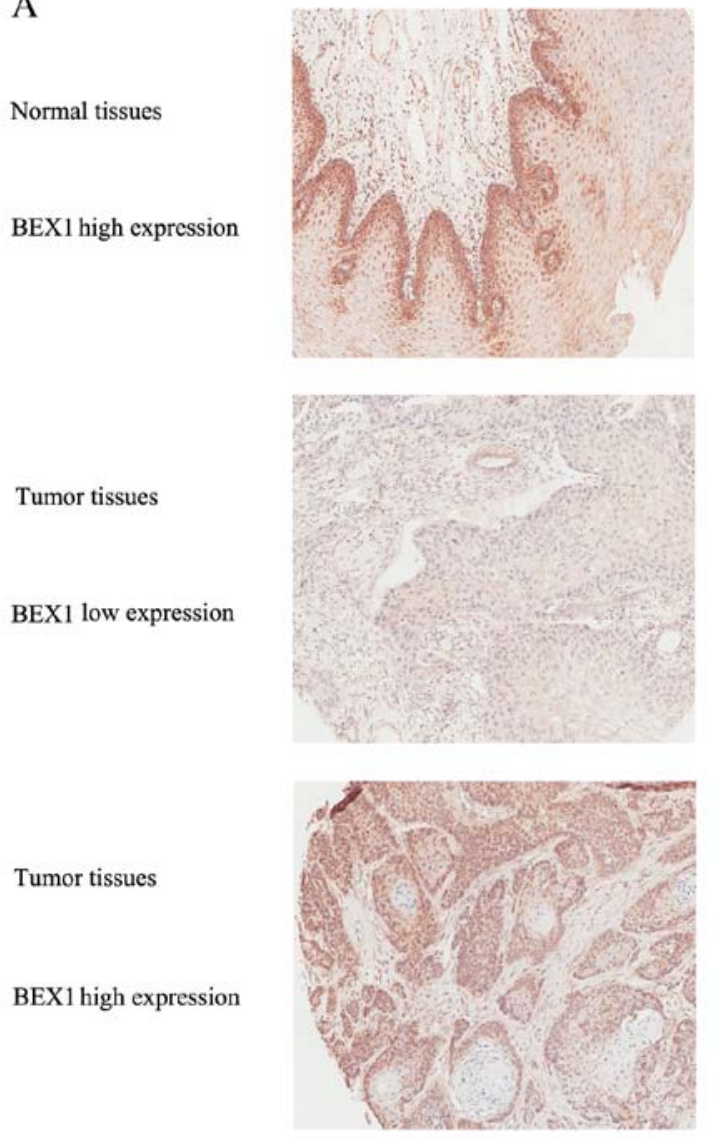

B

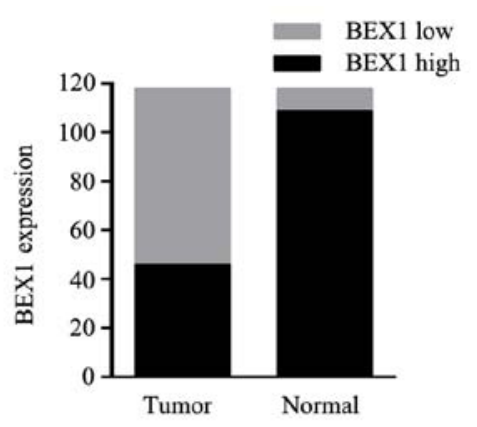

$\mathrm{C}$
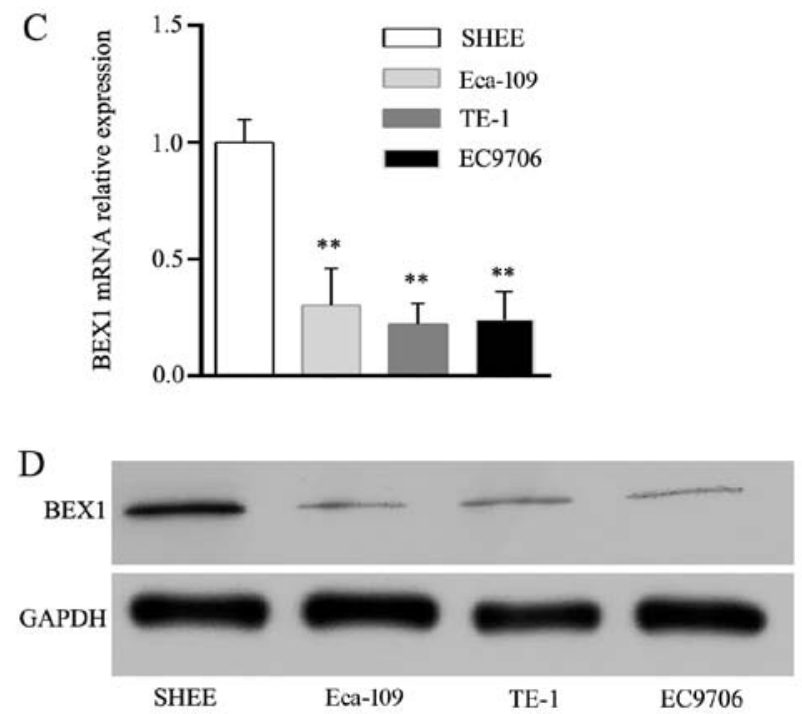

Figure 1. BEX1 expression is downregulated in ESCC tissues and cell lines. (A) Representative immunohistochemical analysis of BEX1 expression in ESCC tumor tissues and corresponding normal tissues (magnification, x100): top image (high in normal tissues); middle image (low in tumor tissues); bottom image (high in tumor tissues). (B) Distribution of tissue BEX1 expression levels in ESCC and normal tissues. (C) BEX1 mRNA expression levels in normal human esophageal epithelial cells (SHEE) and ESCC Eca-109, TE-1 and EC9706 cells were determined by RT-PCR. BEX1 expression levels were normalized to GAPDH expression levels. ${ }^{* *} \mathrm{P}<0.01$. (D) Western blot analysis of BEX1 protein expression in SHEE, Eca-109, TE-1 and EC9706 cells.

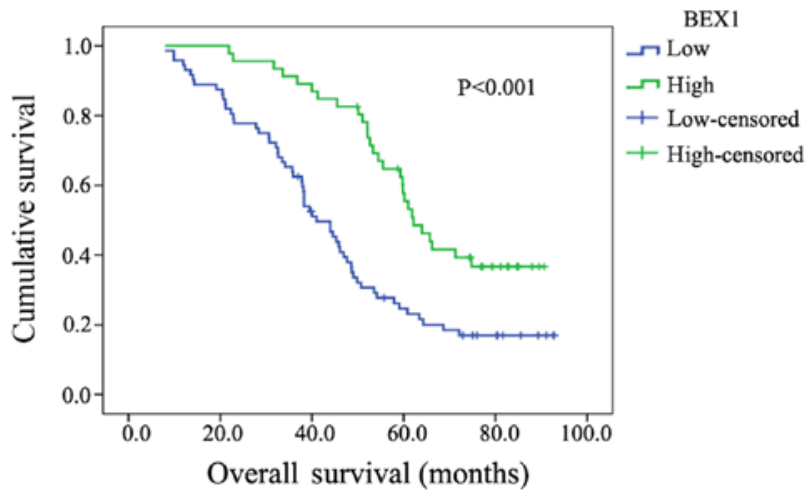

Figure 2. Kaplan-Meier survival analyses for 118 ESCC patients according to BEX1 expression. Cumulative overall survival differences between patients with high and low levels of BEX1 expression $(\mathrm{P}<0.001)$.

BEX1 overexpression inhibits the proliferation and colony formation capacity of ESCC cells. To explore the biological roles of BEX1 in ESCC cancer cells, we transfected TE-1 and Eca-109 cells with BEX1 expression vector to increase BEX1 expression. Western blot analysis and RT-PCR analyses revealed increased BEX1 expression in the transfected TE-1 and Eca-109 cells (Fig. 3A and B). MTT assays revealed that the proliferation of Eca-109 and TE-1 cells was significantly inhibited following BEX1 overexpression in a time-dependent manner (Fig. 3C). Consistent with the decreased cellular proliferation rate, the colony formation assay also revealed that BEX1 overexpression inhibited the colony formation ability of TE-1 and Eca-109 cells (Fig. 3D). To examine whether BEX1 affected the ability of cell proliferation by altering cell cycle progression or apoptosis, we analyzed cell cycle distribution and apoptosis via flow cytometry. We observed that ectopic BEX1 overexpression did not significantly change the cell cycle distribution or apoptosis rates of ESCC cells (Fig. 3E). These results demonstrated that overexpression of BEX1 inhibited the proliferation ability of ESCC cells in vitro.

Overexpression of BEX1 inhibits ESCC tumor growth in vivo. To extend our in vitro observations, we assessed the effect of BEX1 overexpression on tumor growth in mouse xenograft models. TE-1 cells stably expressing BEX1 or control cells were subcutaneously injected into the flank of nude mice and the tumor growth was monitored. The tumor volume was measured every 4 days, and the tumor weight was measured and analyzed 24 days after injection. We observed that BEX1-overexpressing TE-1 xenografts grew significantly slower than the control xenografts (Fig. 4A and B). Consistently, the tumor weights from the BEX1-overexpressing group were significantly lower than those from the control group (Fig. 4C). 
A

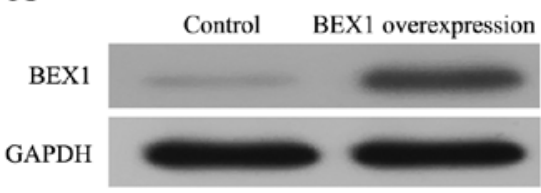

B

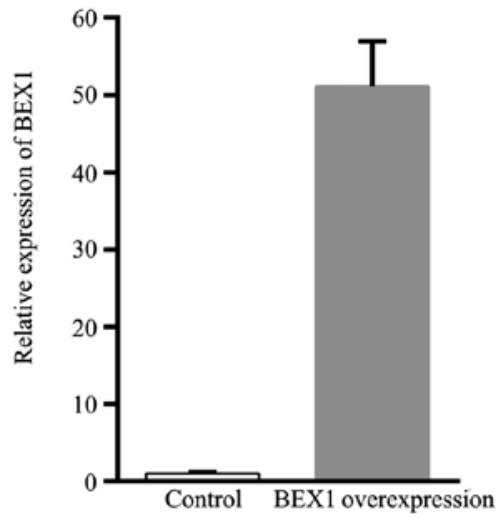

C

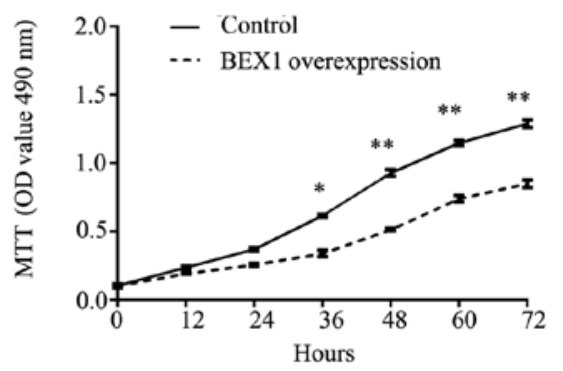

D

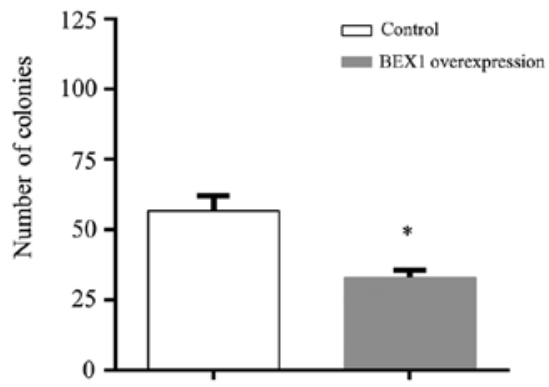

$\mathrm{E}$

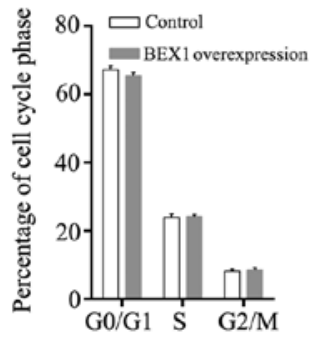

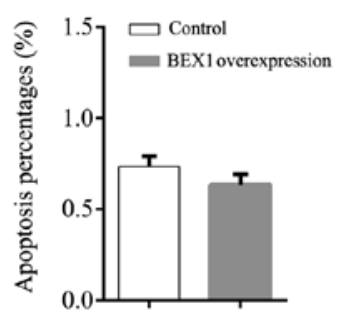
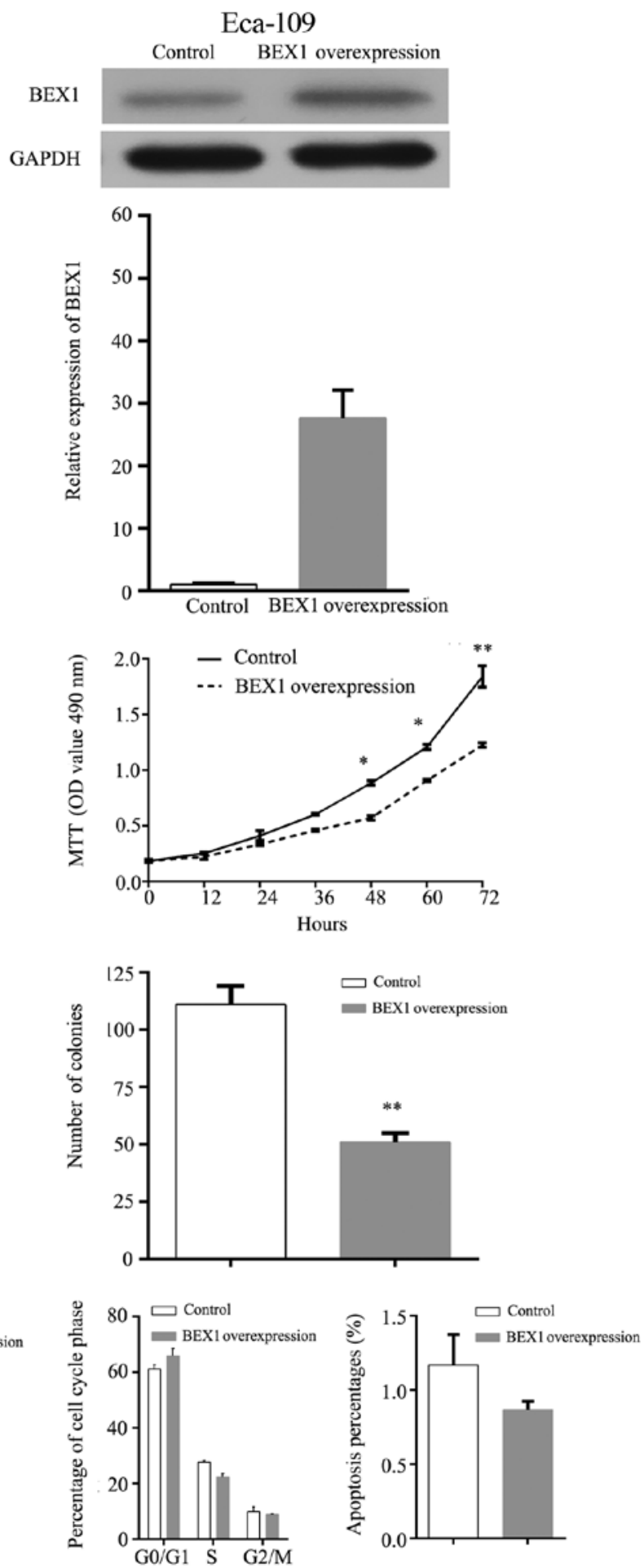

Figure 3. Overexpression of BEX1 inhibits ESCC cell proliferation and colony formation. (A) Increased protein levels of BEX1 in TE-1 and Eca-109 cells following transfection were detected by western blotting. (B) Increased mRNA levels of BEX1 in TE-1 and Eca-109 cells following transfection were assessed by RT-PCR analysis. BEX1 expression levels were normalized to GAPDH expression levels. (C) The proliferation of TE-1 and Eca-109 cells following BEX1 transfection was determined using MTT assay. (D) Colony formation ability of TE-1 and Eca-109 cells following BEX1 transfection was assessed. (E) Cell cycle analysis via flow cytometry following BEX1 transfection. ${ }^{*} \mathrm{P}<0.05{ }^{* * *} \mathrm{P}<0.01$.

These data demonstrated that BEX1 inhibited ESCC tumor growth in vivo.

Overexpression of BEX1 inhibits the activity of the $N F-\kappa B$ signaling pathway. To investigate the underlying mechanisms by which BEX1 inhibited the proliferation of ESCC cells, we firstly examined the activity of the PI3K/AKT pathway, a canonical cell growth-promoting signaling pathway, in TE-1 and Eca-109 cells with or without stable BEX1 expression. We revealed that there was no marked change in both total AKT and phosphorylated-AKT (pAKT) levels between cells with and without BEX1 overexpression in TE-1 and Eca-109 cell lines (Fig. 5A). The p65 subunit is an important member of canonical $N F-\kappa B$ and plays a critical role in cell 
Table II. Univariate and multivariate analysis of survival associated factors.

\begin{tabular}{|c|c|c|c|c|}
\hline \multirow[b]{3}{*}{ Parameters } & \multicolumn{4}{|c|}{ OS (5 year) } \\
\hline & \multicolumn{2}{|c|}{ Univariate analysis } & \multicolumn{2}{|c|}{ Multivariate analysis } \\
\hline & HR $(95 \% \mathrm{CI})$ & P-value & HR $(95 \% \mathrm{CI})$ & P-value \\
\hline Sex (male vs. female) & $0.732(0.413-1.299)$ & 0.286 & $0.549(0.272-1.110)$ & 0.095 \\
\hline Age ( $<60$ vs. $\geq 60$ years $)$ & $1.066(0.698-1.627)$ & 0.767 & $1.289(0.821-2.014)$ & 0.272 \\
\hline Smoking (never vs. heavy) & $1.392(0.882-2.197)$ & 0.155 & $1.403(0.741-2.660)$ & 0.299 \\
\hline Drinking (never vs. heavy) & $1.178(0.761-1.824)$ & 0.463 & $0.594(0.318-1.108)$ & 0.102 \\
\hline Tumor length ( $<4$ vs. $\geq 4 \mathrm{~cm})$ & $2.134(1.327-3.431)$ & 0.002 & $1.070(0.595-1.926)$ & 0.821 \\
\hline $\begin{array}{l}\text { Differentiation } \\
\text { (poor vs. moderate and well } \\
\text { differentiated) }\end{array}$ & $1.145(0.645-2.031)$ & 0.645 & $0.619(0.329-1.163)$ & 0.136 \\
\hline T stage (T1-2 vs. T3-4) & $3.497(1.886-6.484)$ & 0.000 & $2.298(1.108-4.765)$ & 0.034 \\
\hline N stage (N0 vs. N1-3) & $2.361(1.517-3.675)$ & 0.000 & $1.875(1.191-2.952)$ & 0.007 \\
\hline pTNM stage (I, II vs. III) & $2.825(1.807-4.419)$ & 0.000 & $2.160(1.061-4.401)$ & 0.025 \\
\hline BEX1 (low vs. high) & $0.425(0.269-0.670)$ & 0.000 & $0.565(0.329-0.971)$ & 0.039 \\
\hline
\end{tabular}

OS, overall survival; HR, hazard ratio; CI, confidence interval.

A

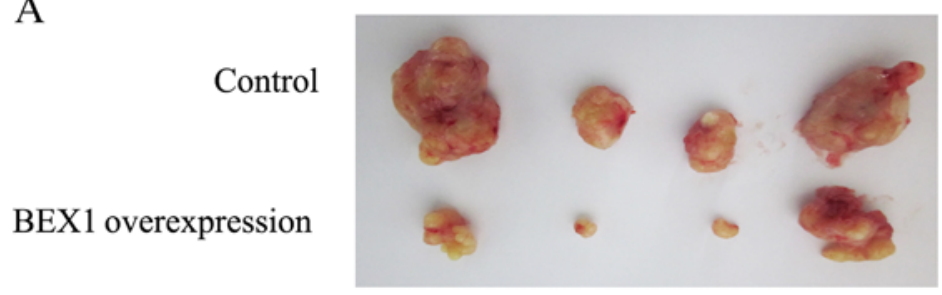

B

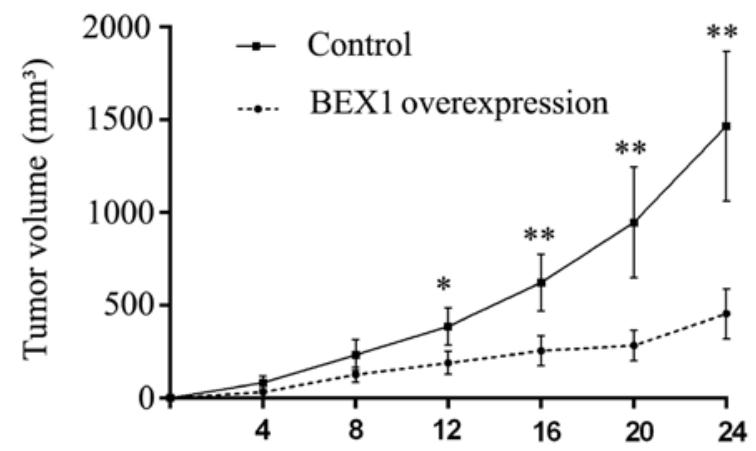

$\mathrm{C}$

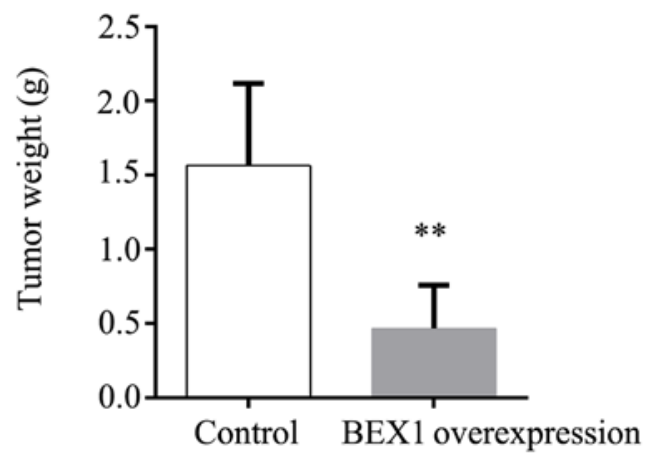

Figure 4. Overexpression of BEX1 inhibits ESCC tumor growth in vivo. (A) The xenografts excised from nude mice (n=4). (B) Tumor volumes and (C) tumor weights were determined on the indicated days. Results are expressed as the mean $\pm \mathrm{SD}$. ${ }^{*} \mathrm{P}<0.05$; ${ }^{* *} \mathrm{P}<0.01$. 
TE-1

A

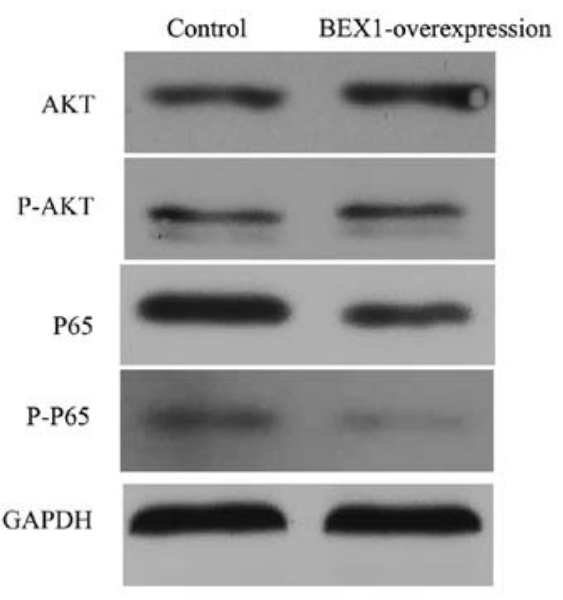

B

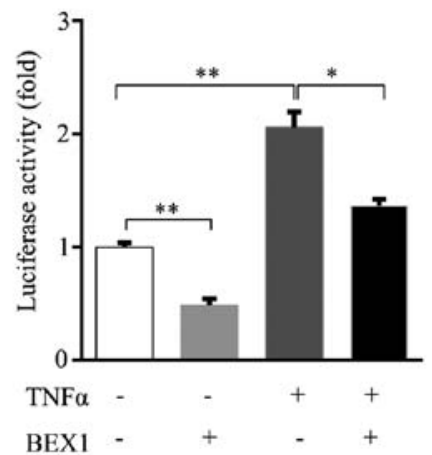

Eca-109
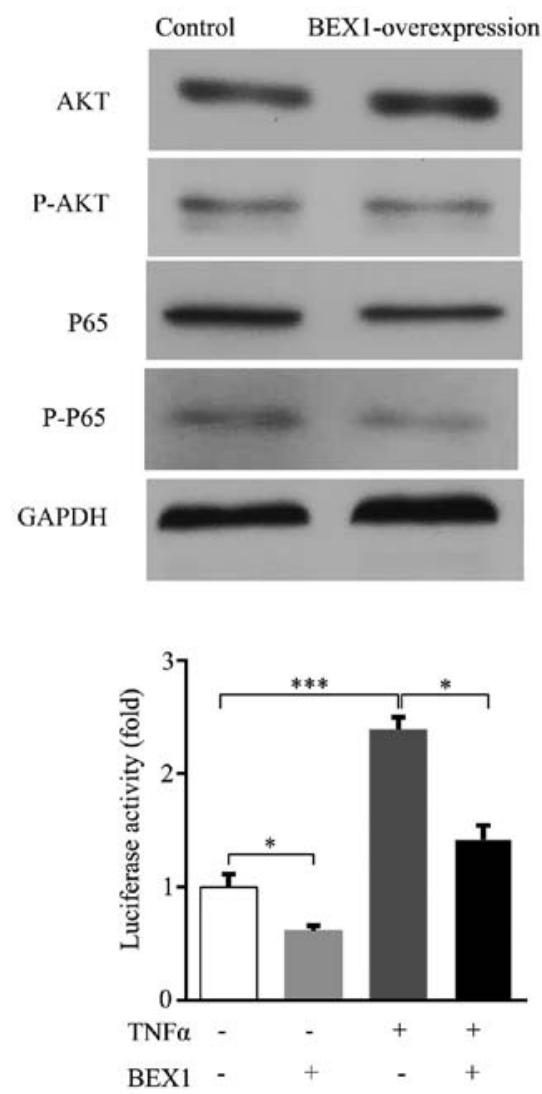

Figure 5. Overexpression of BEX1 suppresses the activity of the NF- $\kappa$ B signaling pathway. (A) Western blot analysis was used to analyze the indicated protein in TE-1 and Eca-109 cells following BEX1 overexpression. (B) The baseline and TNF $\alpha$-stimulated NF- $\kappa$ B activation in TE-1 and Eca-109 cells were analyzed by $\mathrm{NF}-\kappa \mathrm{B}-$ luciferase reporter assays. Transfections were conducted in triplicates. ${ }^{*} \mathrm{P}<0.05 ;{ }^{* *} \mathrm{P}<0.01 ;{ }^{* * * *} \mathrm{P}<0.001$.

proliferation of ESCC cells. A previous study demonstrated a close association of BEX1 with the $\mathrm{NF}-\kappa \mathrm{B}$ signaling pathway in OSCC (11). Therefore, we speculated that BEX1 may play tumor-suppressive roles via the $\mathrm{NF}-\kappa \mathrm{B}$ signaling pathway in ESCC. To test our hypothesis, we examined total p65 and phosphorylated-p65 (p-p65) expression levels after overexpression of BEX1 in TE-1 and Eca-109 cells. Immunoblotting revealed that overexpression of BEX1 decreased both p65 and p-p65 levels (Fig. 5A). In addition, NF- $\kappa$ B-luciferase reporter assays revealed that $\mathrm{BEX} 1$-overexpresson significantly inhibited $\mathrm{NF}-\kappa \mathrm{B}$ activation and prevented $\mathrm{TNF} \alpha$-stimulated $\mathrm{NF}-\kappa \mathrm{B}$ activation in both TE-1 and Eca-109 cells (Fig. 5B). These results indicated that overexpression of BEX1 inhibited ESCC proliferation via the downregulation of the $\mathrm{NF}-\kappa \mathrm{B}$ signaling pathway.

\section{Discussion}

Aberrant expression of BEX1 has been observed in AML, CML, intracranial ependymoma, malignant glioma and OSCC (8-12). In breast, gliomas and colorectal cancers, BEX2 was found to be upregulated and BEX2 overexpression enhanced cell proliferation (13-18), indicating BEX2 to be a putative oncogene. However, BEX4 downregulation was also reported to promote the growth of OSCC, suggesting a tumor suppressor role of BEX4 in OSCC (12). Therefore, the exact functions of BEX1 in tumorigenesis remain elusive and warrant further extensive investigation in different types of cancers with the advent of precision cancer medicine.

Recent studies have revealed BEX1 to be downregulated in OSCC, which has similar etiology and biological phenotypes as ESCC $(11,12)$. However, at present, little is known about the expression level and function of BEX1 in ESCC. In the present study, we investigated the expression of BEX1 in ESCC tumors and cell lines and found that BEX1 expression was downregulated ESCC tissues and cell lines compared to normal tissues. Moreover, low expression of BEX1 was associated with longer tumor length, as well as more advanced $\mathrm{T}$ stages and clinical stages in ESCC patients. Additionally, low BEX1 expression predicted poor prognosis of ESCC patients. Tumor size and $\mathrm{T}$ stage are significantly correlated with cancer cell proliferation. In the present study, we determined that BEX1 overexpression markedly inhibited ESCC cell proliferation in vitro and tumor growth in vivo. In agreement with our findings, BEX1 expression was recently found to be downregulated in 27 out of 40 pediatric intracranial ependymoma tissues, and overexpression of BEX1 to significantly suppress cell proliferation and colony formation (10). Similarly, Lee et al found that the mRNA expression level of BEX1 was significantly lower in OSCC patients with alcohol consumption, betel quid chewing and cigarette smoking, and BEX1 demonstrated potent growth inhibitory activities in 
OSCC cell culture and mouse xenografts (11). Collectively, our findings revealed that BEX1 may function as a tumor suppressor by inhibiting the proliferation and survival of ESCC cells.

Emerging evidence suggests that BEX1 may be involved in the regulation of cell apoptosis and cell cycle progression. In AML, BEX1 induced cell apoptosis by selectively inhibiting FLT3-ITD-induced AKT phosphorylation, without directly interacting with FLT3-ITD (8). In malignant glioma, BEX1 and BEX2 down-regulation resulting from promoter hypermethylation led to increased sensitivity of glioma cells to camptothecin-induced apoptosis (19). Furthermore, BEX1 was found to re-sensitize K562 cells to imatinib-induced apoptosis by binding to B-cell lymphoma 2 (BCL-2) $(9,20)$. Inconsistent with the previous studies, we observed no evident alteration of cell cycle distribution and apoptosis following BEX1 overexpression, indicating that BEX1 regulates cancer cell proliferation and proliferation via multiple mechanisms.

It has been well established that NF- $\kappa \mathrm{B}$ plays an important role in the regulation of inflammation, apoptosis, angiogenesis as well as tumorigenesis (21). Activation of $\mathrm{NF}-\mathrm{kB}$, characterized by phosphorylation of the p65 subunit, is closely associated with the initiation and progression of many types of cancers including ESCC (22-24). NF-kB p65 is overexpressed in human ESCC tissues and NF- $\mathrm{KB}$ activation was revealed to be associated with aggressive clinical biology and poor treatment outcome of ESCC patients (25-27). In addition, blockade of the NF- $\mathrm{\kappa B}$ pathway by suppression of p65 not only inhibited cell proliferation, but also suppressed the invasion and metastasis of ESCC cells (28-31). Previous studies have disclosed a close functional linkage between BEX family members and the NF- $\mathrm{KB}$ signaling pathway $(11,31)$. The potential role of BEX1 in the inhibition of ESCC proliferation via regulation of the NF- $\kappa$ B pathway remained unknown. Our results reevaled that $\mathrm{p} 65$ expression was suppressed in BEX1-overexpressed ESCC cells. Notably, our results demonstrated that both the constitutive and TNF $\alpha$-stimulated activation of NF- $\kappa \mathrm{B}$ signaling were markedly inhibited by BEX1-overexpression. Our findings indicated that the NF- $\kappa \mathrm{B}$ pathway may participate in BEX1-regulated ESCC initiation and progression (data not shown). However, further investigations are required to determine how BEX1 inhibits $\mathrm{NF}-\kappa \mathrm{B}$ activation in ESSC cells.

In conclusion, our study revealed that BEX1 expression was downregulated in ESCC and that low expression of BEX1 was significantly associated with longer tumor length, more advanced $\mathrm{T}$ stage and more advanced pTNM stage. Moreover, low expression of BEX1 was associated with poor clinical outcome of ESCC patients and was an independent prognostic factor for overall survival. In addition, overexpression of BEX1 inhibited ESCC cell proliferation and colony formation in vitro accompanied with suppression of the NF- $\kappa \mathrm{B}$ signaling pathway, and tumor growth in vivo. Our findings collectively indicated that BEX1 may function as a tumor suppressor by suppressing proliferation and growth of ESCC tumors.

\section{Acknowledgements}

Not applicable.

\section{Funding}

The present study was funded by the Beijing Medical and Health Foundation (no. B17126), the Projects of Medical and Health Technology Development Program of Shandong Province (no. 2015WSB30011) and the Science and Technology Planning Project of Binzhou Medical University (no. BY2011KJ030).

\section{Availability of data and materials}

The datasets used during the present study are available from the corresponding author on reasonable request.

\section{Authors' contributions}

HTG, ZWC and YFC designed the study. HTG, ZWC, RJC, ZBW, SZX and CG collected and analyzed the data. RJC, FW and CML advised on histological staining and analysis. SZX, $\mathrm{CG}, \mathrm{FW}$ and $\mathrm{CML}$ contributed to the sample collection and intellectual input. HTG, ZWC and RJC drafted and wrote the manuscript. SSC and YFC revised the manuscript critically for intellectual content. All authors gave intellectual input to the study and approved the final version of the manuscript. All authors read and approved the manuscript and agree to be accountable for all aspects of the research in ensuring that the accuracy or integrity of any part of the work are appropriately investigated and resolved.

\section{Ethics approval and consent to participate}

This study was approved by the Ethics Committee of Binzhou Medical University Hospital. All procedures performed in studies involving human participants were in accordance with the ethical standards of the institutional and national research committee and with the 1964 Helsinki declaration and its later amendments or comparable ethical standards. Written informed consent was obtained from all individual participants included in the present study. The Animal Committee of Binzhou Medical University approved all the experimental protocols and animal handling procedures. All experimental procedures and postoperative animal care were conducted in accordance with the guidelines for the Care and Use of Laboratory Animals from the National Institutes of Health (Bethesda, MD, USA).

\section{Patient consent for publication}

Not applicable.

\section{Competing interests}

The authors declare that they have no competing interests.

\section{References}

1. Torre LA, Bray F, Siegel RL, Ferlay J, Lortet-Tieulent J and Jemal A: Global cancer statistics, 2012. CA Cancer J Clin 65: 87-108, 2015.

2. Chen W, Zheng R, Baade PD, Zhang S, Zeng H, Bray F, Jemal A $\mathrm{Yu}$ XQ and He J: Cancer statistics in China, 2015. CA Cancer J Clin 66: 115-132, 2016. 
3. Wu M, Liu AM, Kampman E, Zhang ZF, Van't Veer P, Wu DL, Wang PH, Yang J, Qin Y, Mu LN, et al: Green tea drinking, high tea temperature and esophageal cancer in high- and low-risk areas of Jiangsu Province, China: A population-based case-control study. Int J Cancer 124: 1907-1913, 2009.

4. Paul S and Altorki N: Outcomes in the management of esophageal cancer. J Surg Oncol 110: 599-610, 2014.

5. Alvarez E, Zhou W, Witta SE and Freed CR: Characterization of the Bex gene family in humans, mice, and rats. Gene 357: 18-28, 2005.

6. Zhang L: Adaptive evolution and frequent gene conversion in the brain expressed X-linked gene family in mammals. Biochem Genet 46: 293-311, 2008.

7. Quentmeier H, Tonelli R, Geffers R, Pession A, Uphoff CC and Drexler HG: Expression of $B E X 1$ in acute myeloid leukemia with MLL rearrangements. Leukemia 19: 1488-1489, 2005.

8. Lindblad O, Li T, Su X, Sun J, Kabir NN, Levander F, Zhao H, Lu G, Rönnstrand L and Kazi JU: BEX1 acts as a tumor suppressor in acute myeloid leukemia. Oncotarget 6: 21395-21405, 2015.

9. Ding K, Su Y, Pang L, Lu Q, Wang Z, Zhang S, Zheng S, Mao J and Zhu Y: Inhibition of apoptosis by downregulation of $h B e x 1$, a novel mechanism, contributes to the chemoresistance of $B c r / A b l^{+}$ leukemic cells. Carcinogenesis 30: 35-42, 2009.

10. Karakoula K, Jacques TS, Phipps KP, Harkness W, Thompson D, Harding BN, Darling JL and Warr TJ: Epigenetic genome-wide analysis identifies $B E X 1$ as a candidate tumour suppressor gene in paediatric intracranial ependymoma. Cancer Lett 346: 34-44, 2014.

11. Lee CH, Wong TS, Chan JY, Lu SC, Lin P, Cheng AJ, Chen YJ, Chang JS, Hsiao SH, Leu YW, et al: Epigenetic regulation of the X-linked tumour suppressors $B E X 1$ and $L D O C 1$ in oral squamous cell carcinoma. J Pathol 230: 298-309, 2013.

12. Gao W, Li JZ, Chen SQ, Chu CY, Chan JY and Wong TS: Decreased brain-expressed X-linked 4 (BEX4) expression promotes growth of oral squamous cell carcinoma. J Exp Clin Cancer Res 35: 92, 2016.

13. Naderi A, Liu J and Francis GD: A feedback loop between BEX2 and ErbB2 mediated by c-Jun signaling in breast cancer. Int J Cancer 130: 71-82, 2012.

14. Naderi A, Teschendorff AE, Beigel J, Cariati M, Ellis IO, Brenton JD and Caldas C: BEX2 is overexpressed in a subset of primary breast cancers and mediates nerve growth factor/nuclear factor-kappaB inhibition of apoptosis in breast cancer cell lines. Cancer Res 67: 6725-6736, 2007.

15. Fischer C, Drexler HG, Reinhardt J, Zaborski $M$ and Quentmeier H: Epigenetic regulation of brain expressed X-linked-2, a marker for acute myeloid leukemia with mixed lineage leukemia rearrangements. Leukemia 21: 374-377, 2007.

16. Zhou X, Xu X, Meng Q, Hu J, Zhi T, Shi Q and Yu R: Bex2 is critical for migration and invasion in malignant glioma cells. J Mol Neurosci 50: 78-87, 2013.

17. Zhou X, Meng Q, Xu X, Zhi T, Shi Q, Wang Y and Yu R: Bex2 regulates cell proliferation and apoptosis in malignant glioma cells via the c-Jun NH2-terminal kinase pathway. Biochem Biophys Res Commun 427: 574-580, 2012.
18. Hu Y, Xiao Q, Chen H, He J, Tan Y, Liu Y, Wang Z, Yang Q, Shen X, Huang Y, et al: BEX2 promotes tumor proliferation in colorectal cancer. Int J Biol Sci 13: 286-294, 2017.

19. Foltz G, Ryu GY, Yoon JG, Nelson T, Fahey J, Frakes A, Lee H, Field L, Zander K, Sibenaller Z, et al: Genome-wide analysis of epigenetic silencing identifies $B E X 1$ and $B E X 2$ as candidate tumor suppressor genes in malignant glioma. Cancer Res 66: 6665-6674, 2006.

20. Xiao Q, Hu Y, Liu Y, Wang Z, Geng H, Hu L, Xu D, Wang K, Zheng L, Zheng S, et al: BEX1 promotes imatinib-induced apoptosis by binding to and antagonizing BCL-2. PLoS One 9: e91782, 2014.

21. Sethi G, Ahn KS, Sung B and Aggarwal BB: Pinitol targets nuclear factor-kappaB activation pathway leading to inhibition of gene products associated with proliferation, apoptosis, invasion, and angiogenesis. Mol Cancer Ther 7: 1604-1614, 2008.

22. Pikarsky E, Porat RM, Stein I, Abramovitch R, Amit S, Kasem S, Gutkovich-Pyest E, Urieli-Shoval S, Galun E and Ben-Neriah Y: NF-kappaB functions as a tumour promoter in inflammation-associated cancer. Nature 431: 461-466, 2004.

23. Karin M and Greten FR: NF-kappaB: Linking inflammation and immunity to cancer development and progression. Nat Rev Immunol 5: 749-759, 2005.

24. Karin M: Nuclear factor-kappaB in cancer development and progression. Nature 441: 431-436, 2006

25. Wang F, He W, Fanghui P, Wang L and Fan Q: NF-кBP65 promotes invasion and metastasis of oesophageal squamous cell cancer by regulating matrix metalloproteinase- 9 and epithelial-to-mesenchymal transition. Cell Biol Int 37: 780-788, 2013.

26. Kang MR, Kim MS, Kim SS, Ahn CH, Yoo NJ and Lee SH: NF- $\mathrm{KB}$ signalling proteins p50/p105, p52/p100, RelA, and IKKepsilon are over-expressed in oesophageal squamous cell carcinomas. Pathology 41: 622-625, 2009.

27. Izzo JG, Malhotra U, Wu TT, Ensor J, Luthra R, Lee JH, Swisher SG, Liao Z, Chao KS, Hittelman WN, et al: Association of activated transcription factor nuclear factor kappab with chemoradiation resistance and poor outcome in esophageal carcinoma. J Clin Oncol 24: 748-754, 2006.

28. Tian F, Zhang C, Tian W, Jiang Y and Zhang X: Comparison of the effect of p65 siRNA and curcumin in promoting apoptosis in esophageal squamous cell carcinoma cells and in nude mice. Oncol Rep 28: 232-240, 2012.

29. Tian F, Fan T, Jiang Y, Zhang $X$ and Wang $X$ : A small interfering RNA targeting NF- $\mathrm{B}$ p 65 alone or combined with 5-FU inhibits growth of esophageal squamous cell carcinoma in nude mice. Pathol Res Pract 208: 32-38, 2012.

30. Tian F, Zang WD, Hou WH, Liu HT and Xue LX: Nuclear factor- $\kappa \mathrm{B}$ signaling pathway constitutively activated in esophageal squamous cell carcinoma cell lines and inhibition of growth of cells by small interfering RNA. Acta Biochim Biophys Sin 38: 318-326, 2006.

31. Meng Q, Zhi T, Chao Y, Nie E, Xu X, Shi Q, Hua L, Wang L, Zhan W, Wang Y, et al: Bex2 controls proliferation of human glioblastoma cells through NF- $\mathrm{BB}$ signaling pathway. J Mol Neurosci 53: 262-270, 2014. 